has started, since there is evidence that decalcification can be prevented but not reversed by oestrogen therapy. ${ }^{8}$ So though steroids for contraceptive purposes might be stopped about the age of 50, there may be a case for continuing them for other reasons, not least being the suppression of unpleasant menopausal symptoms and the promotion of the well-being that such treated women feel. After the menopause it is not usual to prescribe progestogens, and the oestrogen is given continuously either by implant or by mouth. Careful monitoring is of course essential in these patients, and it has to be said, as usual, that more research is needed-there have been recent reports of abnormalities in blood lipids ${ }^{9}$ and an increased susceptibility to gallstones ${ }^{10}$ in patients given postmenopausal oestrogens.

\footnotetext{
1 Garcia, C. R., Pincus, G. and Rock, J. (1958). American Fournal of Obstetric Gynecology, 75, 82 .

DeCosta, E. J. (1962). J.A.M.A. 181, 122

3 Potts, D. M., and Swyer, G. I. M. (1970). British Medical Bulletin, 26, 26.

Fuertes-de la Haba, A., Pelegrina, I., Bangdiwala, I. S. and HernandezCibes, J. J. (1973). Fournal Reproductive Medicine, 10, 3.

5 Royal College of General Practitioners, Oral Contraceptives and Health London, Pitman Medical, 1974.

6 Frommer, D. J. (1964). British Medical fournal, 2, 349.

7 Davies, M. E. (1964). Year Book of Obstetrics and Gynecology, ed. J. P. Greenhill Chicago. 339.

${ }^{8}$ Aitken, J. M., Hart, D. M., and Lindsay, R., British Medical Fournal, 1973,

Molitch, M. E., Oill, P., and Odell, W. D., fournal of the American Medical

Association, 1974, 227, 522.
10 Boston, Collaborative Drug Surveillance Programme, New England fournal of Medicine, 1974, 290, 15.
}

\section{Blind Children}

Most readers of the $B . M . \mathcal{F}$. have never seen xerophthalmiathe generic term for all the ophthalmic lesions of vitamin A deficiency-or will have recognized it only as an occasional accident of malnutrition. Since Bloch ${ }^{1}$ showed 50 years ago that the disease, then widespread among children in postwar Denmark, could be effectively and easily prevented by cod liver oil and dairy foods it has disappeared from all countries with adequate community medical and welfare services. The cause is now so well understood, while prevention and cure seem so straightforward, that the problem might appear to have no further medical interest.

Ten years ago McLaren ${ }^{2}$ estimated that approximately 20,000 children throughout the world go blind every year from xerophthalmia with keratomalacia. This seems to be an underestimate, for Venkataswamy ${ }^{3}$ has reported that in Madras State alone in 1961 some $9-10,000$ children under 4 years of age were blind owing to keratomalacia. The numbers are increasing with the increasing population of children, increasing poverty, and increasing pressure on food supplies. The disease is closely related to protein-calorie malnutrition, having its worst effects on young children between their first and fifth birthday. Typically it does not occur through simple dietary deficiency of vitamin A but as a complication of general malnutrition, diarrhoea, and the common infections of childhood. It is a part of the general picture of high morbidity and high mortality at weaning. Because it has a complex relationship with protein-calorie malnutrition and affects the poorest and most severely malnourished young children, it is often overlooked, for this most vulnerable group in the community is the least accessible to medical and welfare services.

The incidence of blindness gives little clue to the real incidence of deficiency, for the mortality from keratomalacia is high, and only a minority of children who are deficient in vitamin $\mathrm{A}$ and therefore at risk have xerosis of conjunctiva or cornea. The earliest clinical sign-night-blindness-is the most amenable to treatment. Blankhart, ${ }^{6}$ in a small longitudinal study, found that over a quarter of the children in some Indonesian villages passed through at least one incident of vitamin A deficiency as diagnosed by a simple test for night-blindness.

A disease affecting the sight and survival of masses of children living in poverty cannot be effectively treated by the qualified physician or ophthalmologist working in the outpatient clinic or hospital. The children are dead or blind before they are seen. This has been repeatedly emphasized by Mclaren and Oomen. ${ }^{2-5}$ Schemes for health and nutritional education, however well conceived, are too slow in action to save children who will certainly become blind this year; yet each of them could be saved by a few milligrams out of the tons of retinol synthesized by the pharmaceutical industry, or by some cheap supplement, regularly administered, prepared from readily available local sources of vegetable carotenoids, fish liver oils, or dairy foods.

The medical profession has a clear duty to look for xerophthalmia among the young children of Central and South America, Africa, and Asia, to teach paramedical staff and welfare workers to recognize and treat it, and to organize effective prophylaxis with cheapest available vitamin supplements. To promote measures of this kind which could help to prevent xerophthalmia and to co-ordinate activities and information, the Xerophthalmia Club has been formed under the chairmanship of Professor H. A. P. C. Oomen. ${ }^{7}$ Anybody interested in blind children should join this club.

1 Bloch, C. E., American Fournal of Diseases of Children, 1924, 27, 139. McLaren, D. S., Malnutrition and the Eye. New York and London, Academic Press, 1963.

Causes and Prevention of Blindness, ed. Michaelson, I. C., and Elaine R Berman, New York and London, Academic Press, 1972.

4 Oomen, H. A. P. C., MacLaren, D. S., and Escapini, H., Tropical and Geographical Medicine, 1964 16, 271.

${ }^{5}$ McLaren, D. S., Oomen, H. A. P. C., and Escapini, H., Bulletin of the World Health Organization, 1966, 34, 357.

6 Blankhart, D. M., Tropical and Geographical Medicine, 1967, 19, 144 Secretary, Dr. A. Pirie, Girton College, Cambridge.

\section{Active Chronic Hepatitis}

Active chronic hepatitis has in the past gone by a number of names including lupoid hepatitis, juvenile cirrhosis, and plasma cell hepatitis. The newer term embodies at least two of the essential features of the condition, namely a chronic progressive liver disorder with superimposed episodes of activity. The characteristic histological appearances are those of a chronic aggressive hepatitis, and in untreated cases cirrhosis develops rapidly. Indeed it is present already at time of diagnosis in more than a third of the patients. Little is known of the pathogenesis, though the presence of tissue antibodies reacting with smooth muscle, nuclear, and mitochondrial antigens and the finding of cell-mediated immune responses to a liver-specific cell surface lipoprotein ${ }^{2}$ have suggested that autoimmunity is concerned. Evidence of disease in other organs of an autoimmune nature may also be present, Sjogren's syndrome and renal tubular acidosis being perhaps the most common; these are detectable in about $30 \%$ of cases according to a recent investigation of Golding $e t a l .^{3}$ The disordered immune responses may have a familial basis, for the first degree relatives 